\title{
Facile preparation of spherical cellulose nanoparticles: chemical hydrolysis of fibres with tension
}

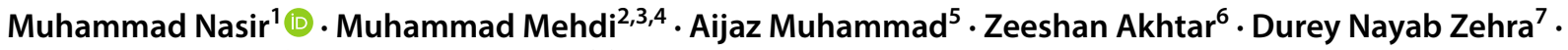 \\ Mohib Raza Kazmi ${ }^{6}$ Muhammad Awais ${ }^{8,9}$
}

Received: 24 September 2019 / Accepted: 6 January 2020 / Published online: 16 January 2020

(c) Springer Nature Switzerland AG 2020

\begin{abstract}
This paper describes a facile approach to prepare cellulose nanoparticles (CNPs) by chemical hydrolysis of cellulose fibres with tension, which eliminates the conventional requirement of high temperature and mechanical agitation/sonication. Furthermore, it gives the advantage of controlled spherical morphology. For this purpose, $60 \mathrm{psi}$ load has been employed perpendicularly to the axis of fibres passing between rollers of different rotations per minute. This mechanism stretches the fibres to produce tension in them. Combing has also been employed to remove inherited immature and short fibres so that only the fibres with uniform tension can be utilized for chemical hydrolysis. The combing enhances uniformity and crystallinity index that were analysed by Uster Uniformity Test and X-ray Diffractogram respectively. Effect of tension was further investigated thermogravimetrically. Morphology of cellulose nanoparticles was studied by Atomic force microscopy that showed 8-16 nm amorphous spherical (CNPs) as the outcome of chemical hydrolysis of fibres with tension.
\end{abstract}

Electronic supplementary material The online version of this article (https://doi.org/10.1007/s42452-020-1970-6) contains supplementary material, which is available to authorized users.

$\triangle$ Muhammad Nasir, dr.muhammadnasir@yahoo.com | 'Department of Chemistry, Adamjee Government Science College, Off Business Recorder Road, Karachi 74500, Pakistan. ${ }^{2}$ Department of Metallurgy and Materials Engineering, Dawood University of Engineering and Technology, M.A Jinnah Road, Karachi 74800, Pakistan. ${ }^{3}$ Hydrogen Laboratory, Korea Institute of Energy Research, 152 Gajeong-ro, Yuseong-gu, Daejeon 34129, Republic of Korea. ${ }^{4}$ Department of Advanced Energy and System Engineering, University of Science

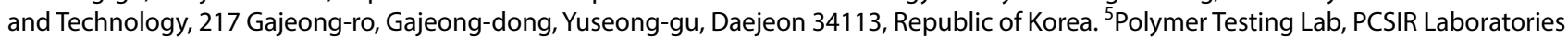
Complex, Off University Road, Karachi 75280, Pakistan. ${ }^{6}$ Department of Applied Chemistry and Chemical Technology, University of Karachi, Main University Road, Karachi 75270, Pakistan. ${ }^{7}$ Department of Chemistry, Government Degree Girls College Al-Noor, F.B Area, Karachi 75950, Pakistan. ${ }^{8}$ Photovoltaic Laboratory, Korea Institute of Energy Research, 152 Gajeong-ro, Yuseong-gu, Daejeon 34129, Republic of Korea. ${ }^{9}$ Department of Renewable Energy Engineering, University of Science and Technology, 217 Gajeong-ro, Gajeong-dong, Yuseong-gu, Daejeon 34113, Republic of Korea. 


\section{Graphic abstract}

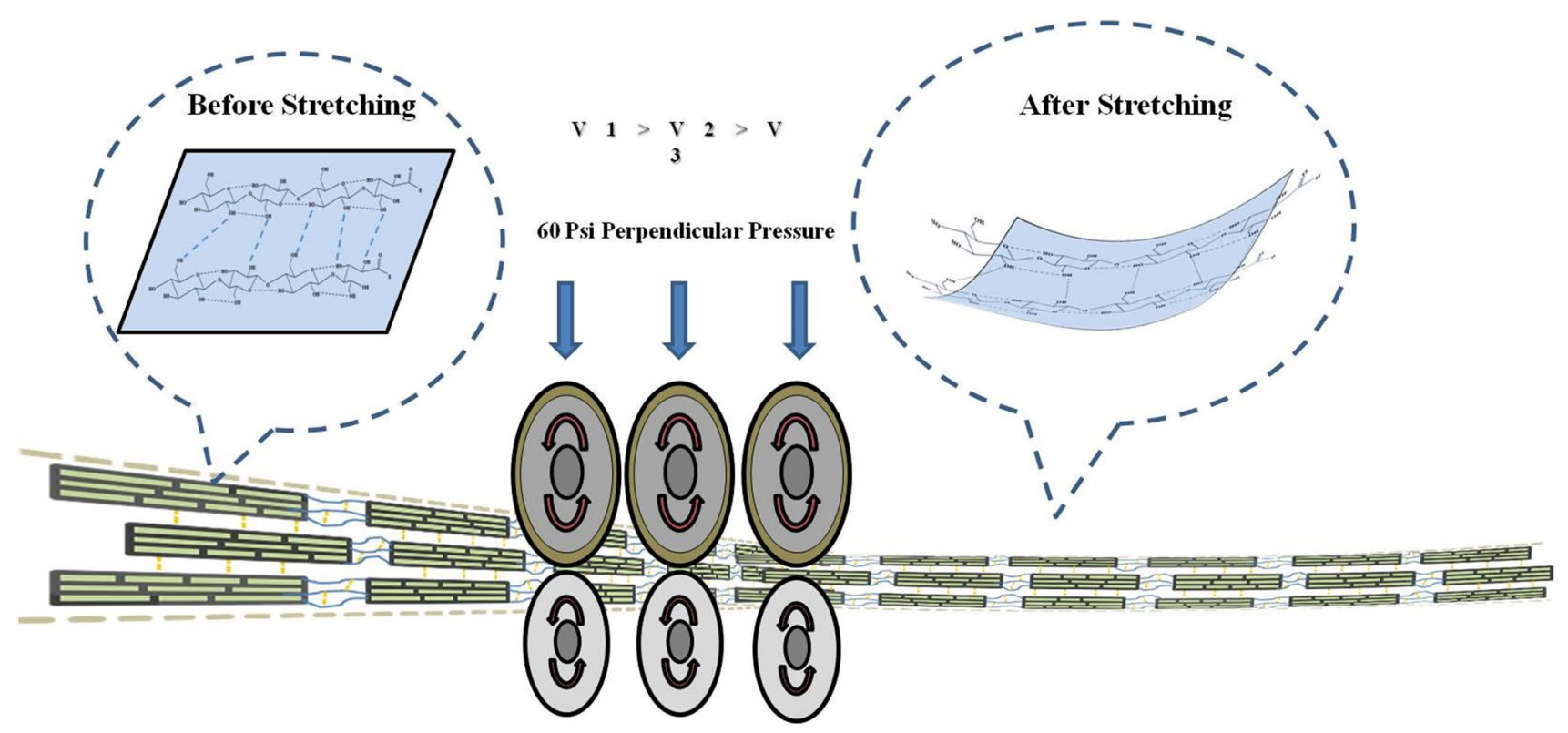

(a) Drafting of a fibre
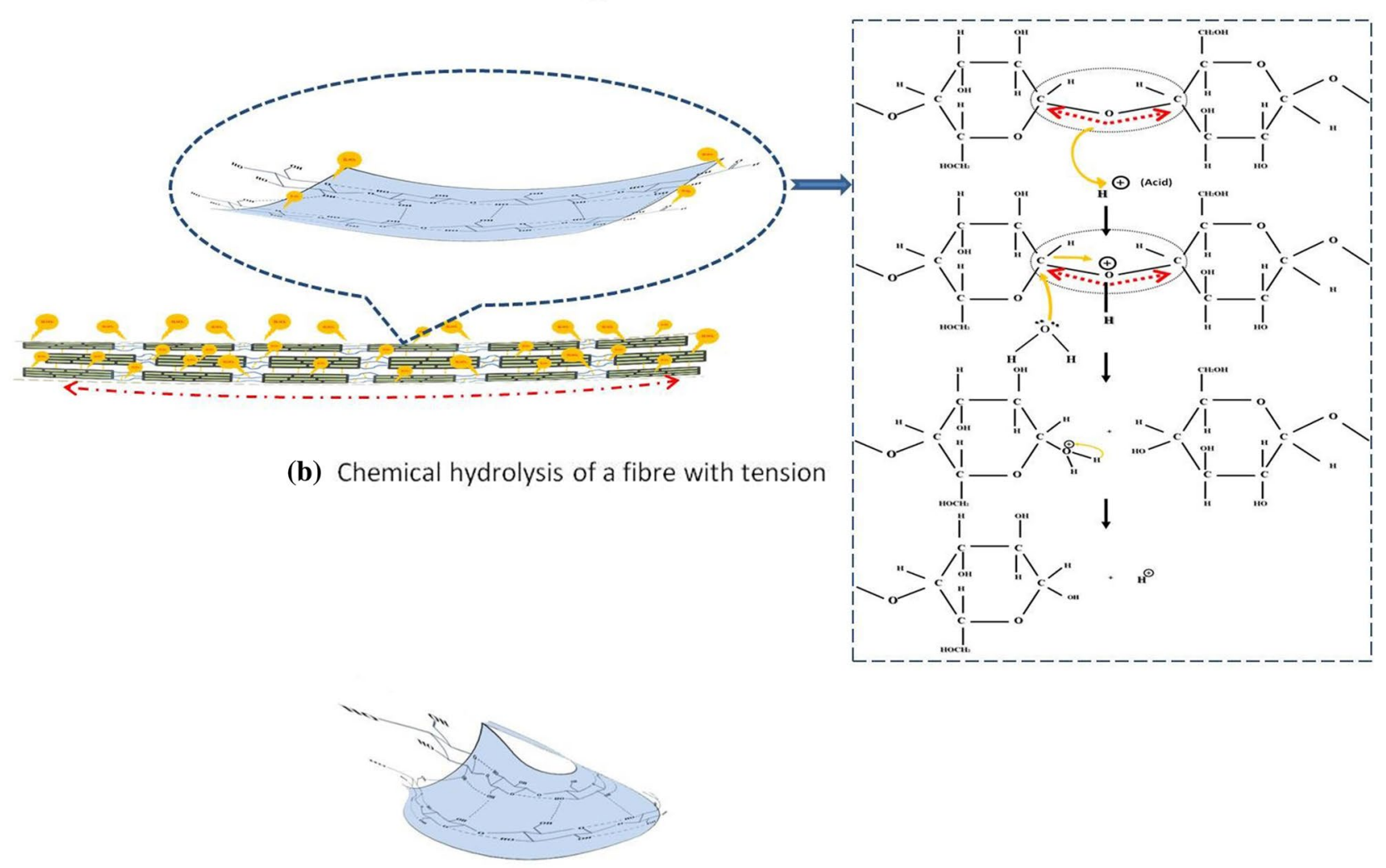

(c) Spherically wrapped cellulose nanoparticle

Keywords Chemical hydrolysis · Cellulose fibres with tension · Spherical nanoparticles · Uniformity of fibres · Crystallinity index 


\section{Introduction}

Cellulose fibres are the biopolymer build from the bundles of very fine fibrils with nano-scale diameter, and these nano-fibrils are comprises of $60-80 \%$ highly ordered crystallites and rest are mesomorphous and amorphous domains $[27,41]$. Numerous crystallites and disordered domains are present within an individual cellulose chain structure which are interconnected with 1, 4- $\beta$-glycoside linkages [15] and stabilised by hydrogen bonding. In an anhydroglucose unit of cellulose, there are three kinds of hydroxyl groups which exhibit different polarities that are the reason for hydrogen bonding between secondary $-\mathrm{OH}$ at $\mathrm{C} 2$, secondary $-\mathrm{OH}$ at $\mathrm{C} 3$ and primary - $\mathrm{OH}$ at C6. Whereas, with the glucopyranose ring each hydroxyl group is bonded equatorially while $-\mathrm{CH}$ groups are attached axially. This is because hydrophilic and hydrophobic sites appear parallel and perpendicular to the ring respectively. These effects architect the hydrogen bonding parallel to the glucopyranose ring and van der Waals interaction in perpendicular $[17,25]$.

Cellulose nanoparticles (CNPs) are earning curiosity amongst researchers due to their versatile applications in biomedical [4, 18], nano-composites [7], bio-electrodes [21] pharmacy [24], food [26], textile [35] and many other industries. These broad applications are because of their nanosize, high strength [1], low weight [8], good rheology $[32,33]$, fine optical properties [12] and inertness to many substances [13, 25].

Cotton fibres are the purest source of the cellulose fibres while in wood and other parts of the plants, it is found with lignin, hemicelluloses and other high content impurities. Therefore, cotton fibres are the first choice to prepare CNPs $[19,20]$. Traditionally, mechanical homogenization process is used for mass production of CNPs which requires energy consumption of 20,000 to $30,000 \mathrm{kWh}$ per tonne which is 4 to 5 times of potential energy of biomass [33].

The inter-fibrillar hydrogen bonding energy has to be overcome for the preparation of CNPs which ranges between 19 and $21 \mathrm{MJ} / \mathrm{kg} \mathrm{mol}$ [3] due to which fibrous and crystalline CNPs are comparably easy to prepare rather than spherical and amorphous CNPs [6, 34]. Nevertheless, many scientists reported the preparation of spherical CNPs by using the modified effect of common parameters; strong chemical hydrolysis, high mechanical agitation/sonication and elevated temperature. As reported, some of them performed milling before hydrolysis [10, $22,40]$ while some have used cotton waste by textile mill [9] or waste cotton fabric [38]. Moreover, Han et al. [11] reported the formation of spherical nanoparticles by highpressure homogenization. Interestingly, all of these preparation methods involve the role of tension in fibres which weakens their intermolecular and intramolecular bonding. It is understandable that the milling process produces tension in cellulose fibres. Similarly, waste cotton and waste cotton fabric already have some extent of tension in them as they are the waste of drafted cellulose fibres which will be further elaborated in our manuscript. Lastly, high-pressure homogenization also produces tension in cellulose fibres and weakens its bondings.

Prior research studies have shown the formation of amorphous and spherical nanoparticles as a function of high shear force in the form of milling, sonication and high-pressure homogenization etc. The effect of shear force on the cellulose morphology at a molecular level never been studied.

According to our hypothesis, shear forces impact on intra and intermolecular hydrogen bond in cellulose chains and creates a sort of tension at the micro level and cause the cellulose chain to be disintegrated laterally to produce amorphous and spherical nanoparticles.

Therefore this investigation is designed to assess the hypothesis that fibres with tension can affect the reaction conditions and morphology of nanoparticles to develop a facile and economical method to prepare cellulose nanoparticles via chemical hydrolysis Our findings in this paper are twofold; first, the preparation of spherical CNPs by chemical hydrolysis of cellulose fibres with tension. Second, a deep discussion on the significance of tension as a parameter for the preparation of spherical CNPs by comparing obtained results with previously reported methods. The paper of Altaner et al. [2] explains a mechanism in which the drafting of a cellulose fibre stretches its glycosidic linkage and weakens the hydrogen bonding. In a result, its mechanical stiffness increases synergistically which build tension. This phenomenon makes cellulose fibre much more vulnerable for chemical hydrolysis.

Herein, we utilised spin cellulose fibres obtained from drafting-combing-drafting process to evaluate the effect of tension on reaction parameters and morphology of CNPs. It is found that tension in fibres not only control the morphology of CNPs but reaction conditions as well. In this research study, we successfully prepared spherical and amorphous CNPs of 8-16 nm at ambient temperature without any pre-treatment and post-treatment mechanical stirring or sonification.

\section{Experimental}

\subsection{Materials}

Cellulose fibres of African origin were collected from Fazal Textile Mills in Karachi, Pakistan with average chute feed size of $12.54 \mathrm{~mm}$. Concentrated Sulphuric Acid $\left(\mathrm{H}_{2} \mathrm{SO}_{4}\right)$ 
worked as a hydrolyzing agent and Dimethyl Sulfoxide (DMSO) was used as a solvent. Both the reagents were obtained from Sigma-Aldrich while Sodium Hydroxide $(\mathrm{NaOH})$ was received from Merck. The de-ionized water with $\mathrm{pH}$ value of 6.24 was used for washing and neutralising purpose. All the reagents used were of an analytical grade having $98 \%$ purity.

\subsection{Drafting-combing-drafting process: creating tension and uniformity in fibres}

In a yarn manufacturing textile unit, the sequential drafting-combing-drafting process was applied to achieve equivalent tension and uniformity in each fibre. First, the chute feed of cellulose fibres (average size $12.54 \mathrm{~mm}$ ) which consist of non-uniform long and short fibres was put into a carding machine REITER C-60 (Switzerland) posses of a metallic wire-tooth brush to clean and unwrap cotton fibres into a web and apply initial stretching, leaving behind the short fibres and leafy dust. The output is called sliver. Second, the sliver was shifted into drawing breaker machine REITER SB-2 (Switzerland); where sliver was further attenuated. The 24 attenuated slivers fed into lap-forming machine REITER E-32 (Switzerland) where they were wrapped into a spool to improve their overall uniformity and strength. Third, these laps fed into combing machine REITER E-7/6 to eliminate the ineligible fibres $(\leqq 10 \mathrm{~mm})$ resulting in ultimate structural uniformity in terms of length and mass. Final, the combed fibres were attenuated further by drafting rollers to achieve endmost stretching capacity by the perpendicular pressure of 60 PSI. The average final length is $15.1 \mathrm{~mm}$.

\subsection{Chemical hydrolysis of fibres with tension: preparation and isolation of spherical cellulose nanoparticles}

A collection of fibres with tension ( $5 \mathrm{~g}$ ) were just soaked into $100 \mathrm{ml} 55 \% \mathrm{H}_{2} \mathrm{SO}_{4}(\mathrm{~V} / \mathrm{V} \%)$ at ambient temperature without stirring so that acid can react to the specific weak and amorphous regions that possess tension. A slurry of a thick paste (settled suspension) was achieved after $24 \mathrm{~h}$. This slurry was quenched by five folds of $300 \mathrm{ml}$ cold deionized water and it became a suspension of hydrolyzed cellulose by the addition of $200 \mathrm{ml}$ water. The suspension was left for $24 \mathrm{~h}$ to settle down and then decanted. The process of decantation was performed 10 times with $200 \mathrm{ml}$ of distilled water after every $8 \mathrm{~h}$ until the $\mathrm{pH}$ reaches around 6 . Moreover, $0.1 \mathrm{M} \mathrm{NaOH}$ solution was used to wash and neutralise the $\mathrm{pH}$ of solution and left for $24 \mathrm{~h}$. The solution was again decanted and washed with de-ionized water several times to remove excess alkali followed by freeze drying at $-30^{\circ} \mathrm{C}$ for $24 \mathrm{~h}$. The resultant CNPs were collected in a vial for characterisation. The schematic diagram of the complete preparation procedure is depicted in Fig. 1.

\subsection{Characterization}

\subsubsection{Atomic force microscopy (AFM)}

3D and 2D structures of CNPs were confirmed by AFM-Agilent 5500 . For AFM analysis, $1 \mathrm{mg}$ of CNPs were dissolved in $100 \mathrm{ml}$ moisture-free dimethyl sulfoxide (DMSO) and stirred for $30 \mathrm{~min}$ which was sample A. Then, $1 \mathrm{ml}$ of sample $A$ was further dissolved into $100 \mathrm{ml}$ DMSO and again stirred for next 30 min forming more diluted sample B. Each sample was drop cast on mica sheet and kept in a freeze dryer for $24 \mathrm{~h}$ at $-30^{\circ} \mathrm{C}$ before analysing. The mode of AFM was intermittent contact mode with the resonance frequency of $298.563 \mathrm{kHz}$. The AFM probe was made up of silicon nitride. The resolutions of $3 \mathrm{D}$ and $2 \mathrm{D}$ images are $757 \times 510$ pixels and $378 \times 265$ pixels respectively.

\subsubsection{Uniformity test}

The uniformity of cellulose fibres before and after the drafting-combing-drafting process was measured by using Uster Technologies 4-SX evenness tester as per American Society for Testing and Materials Standard (ASTM) D1425. This instrument uses optoelectronic sensors.

\subsubsection{X-ray diffractograms analysis (XRD)}

XRD was performed by Bruker D8 and Siemens D5000 diffractometer with $\mathrm{Cu} \mathrm{K}$ a in a $2 \theta$ range between $5^{\circ}$ and $90^{\circ}$ with a step time of $1 \mathrm{~s}$ at ambient temperature was performed to evaluate their crystallinity index. The percentage crystallinity index (C.I) of fibres with and without tension was evaluated by Eq. 1 [34].

$\% C . I=\left(I_{c}-I_{o}\right) / I_{C} \times 100$
Fig. 1 Schematic diagram of the preparation procedure

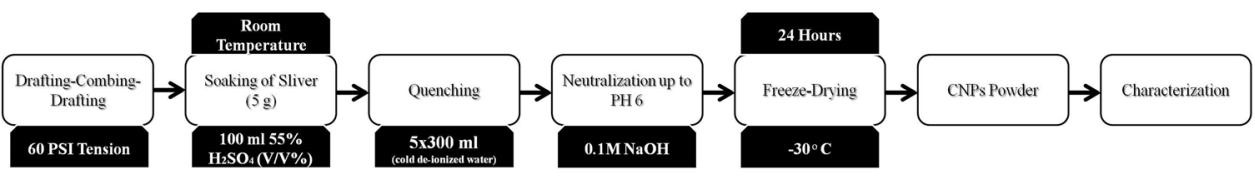


where $I_{c}$ and $I_{a}$ are the maximum and minimum peak intensity. Furthermore, $d$-spacing between rays can be calculated using Bragg's law (Eq. 2):

$\lambda=2 \mathrm{~d} \operatorname{Sin} \theta$

Such that, $\lambda$ refers to the wavelength $(1.54 \AA)$, which is fixed for $\mathrm{Cu} K$ a diffractogram and $\theta$ is the angle between planes in degree. However, the crystallite size $\left(L_{c}\right)$ of CNPs is calculated by Scherrer Equation (Eq. 3).

$L_{c}=K \lambda / \beta \operatorname{Cos} \theta$

where $K$ is the shape factor (0.94) while $\beta$ is the full width at half maximum (FWHM) of the peak angle in radian.

\subsubsection{Thermal gravimetric analysis (TGA)}

The change in thermal property due to tension and morphological transformation was evaluated by thermal gravimetric analysis (TGA/SDTA 851). The dynamic TGA was performed under an inert atmosphere and isobaric conditions up to $600^{\circ} \mathrm{C}$.

\section{Results and discussion}

\subsection{Tension in fibres}

Natural polymers have good ductility due to their long chains and inter-molecular bondings [37]. The glycoside linkage present in the cellulose fibres supports its elongation [2]. The Table 1 shows change in length at each step of the drafting-combing-drafting process as calculated by Eq. 5 . It shows that chute feed elongates $3.74 \%$ after carding. This card sliver was further stretched in breaker machine up to $9.8 \%$. Finally, combed fibres were maximumly attenuated to further $5.5 \%$. The whole process contributes $20.2 \%$ elongation.

$\%$ Elongation $=\left(\left(L_{f}-L_{o}\right) / L_{o}\right) \times 100$

where $L_{o}$ and $L_{f}$ are the initial and final length in each process.

After the process, fibres maintained their tension due to their intermolecular deformation which can be visualised easily macroscopically as shown in Fig. 2. The Fig. 2a shows raw fibres (chute feed) without any tension and Fig. $2 b$ depicts short fibres that were eliminated during the process. Some amount of tension is also visible in them but they were eliminated because of their ineligible length for further steps of processing. While Fig. 2c illustrates ultimate tension in fibres evident by their curly appearance on the surface after having been cut by the scissors.
Table 1 \%Elongation test report after each operation performed in the yarn manufacturing unit of a textile mill

\begin{tabular}{llll}
\hline Test number & Process & Length $(\mathrm{mm})$ & Elongation (\%) \\
\hline 1 & Chute Feed & 12.84 & \\
2 & (Start) & 12.76 & \\
3 & & 12.45 & \\
4 & & 12.1 & \\
Average & & 12.54 & 0 \\
1 & Card Sliver & 12.94 & \\
2 & & 12.82 & \\
3 & & 13.25 & \\
4 & & 13.01 & \\
Average & & 13.01 & 3.74 \\
1 & Breaker & 14.85 & \\
2 & & 14.27 & \\
3 & & 14.14 & \\
4 & & 13.9 & \\
Average & & 14.29 & 9.8 \\
1 & Combed Fibres & 15.15 & \\
2 & (End) & 14.49 & \\
3 & & 15.68 & \\
4 & & 15.01 & \\
Average & & 15.08 & \\
\hline
\end{tabular}

\subsubsection{Mechanism}

The fibres are stretched by applying sequential pressure of 60 psi perpendicularly through drafting rollers moving with different speed. This process not only stretched the glycosidic linkage but also weakened the intermolecular and intramolecular hydrogen bonding in the cellulose chain which can also be visualised at macro level such as fibres elongate after stretching as noted in Table 1. Furthermore, stretching also produce tension in fibres which can be observed by the curliness of short fibres as shown in the Fig. 2c. Previous study by Altaner et al. [2] explained it theoretically that each glucose unit in a cellulose chain is connected by a covalent $\mathrm{C}-\mathrm{O}-\mathrm{C}$ linkage flanked by two hydrogen bonds. This unique geometry allows cooperation between covalent and hydrogen bonding. The applied mechanical tension straightens out this zigzag conformation of the cellulose chain. This straightening at molecular level consequently increases the length of fibre but it is resisted by one of the flanking hydrogen bonds. This constitutes a simple form of molecular leverage with the covalent structure providing the fulcrum and gives the hydrogen bond an unexpectedly amplified effect on the tensile stiffness of the chain.

It is reported that chemical hydrolysis of fibres by $55 \%$ $\mathrm{H}_{2} \mathrm{SO}_{4}$ produces crystalline nano-fibres [14] but in our case, amorphous spherical CNPs were achieved nature due to 

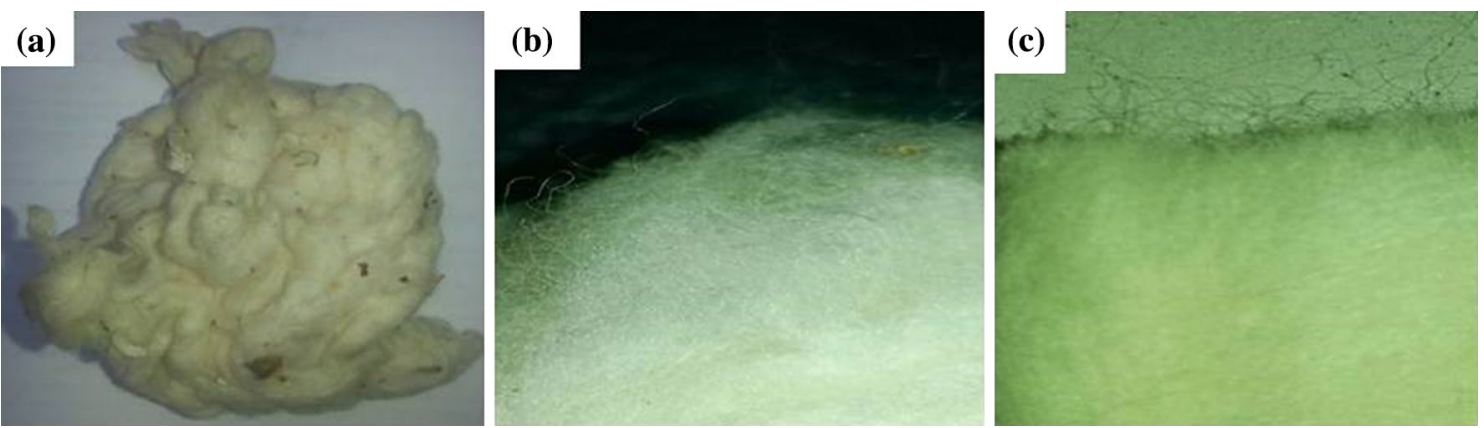

Fig. 2 Effect of tension on fibres. a Raw fibres (chute feed) without tension. b Short eliminated fibres with some tension. c Fibres with tension after complete stretching

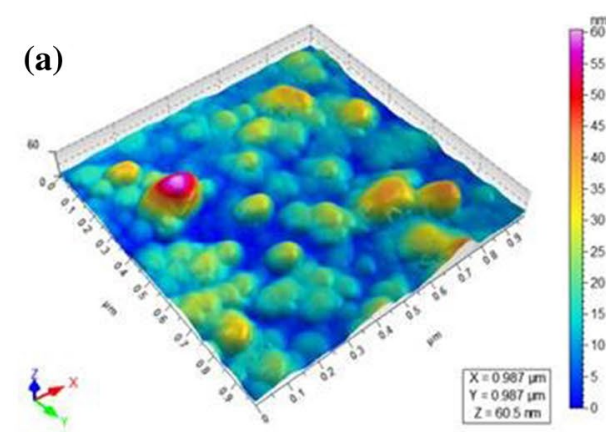

(d)

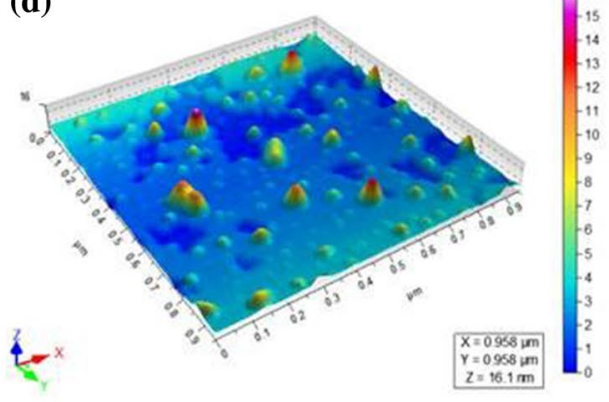

(b)

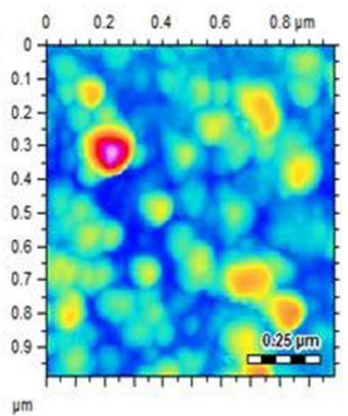

(e)

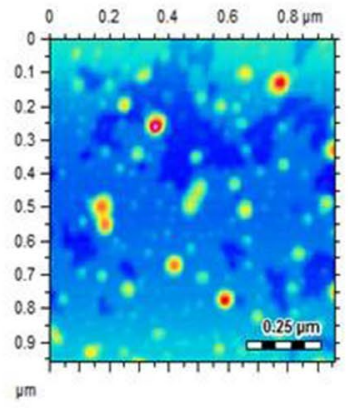

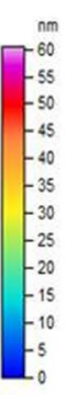

(c)
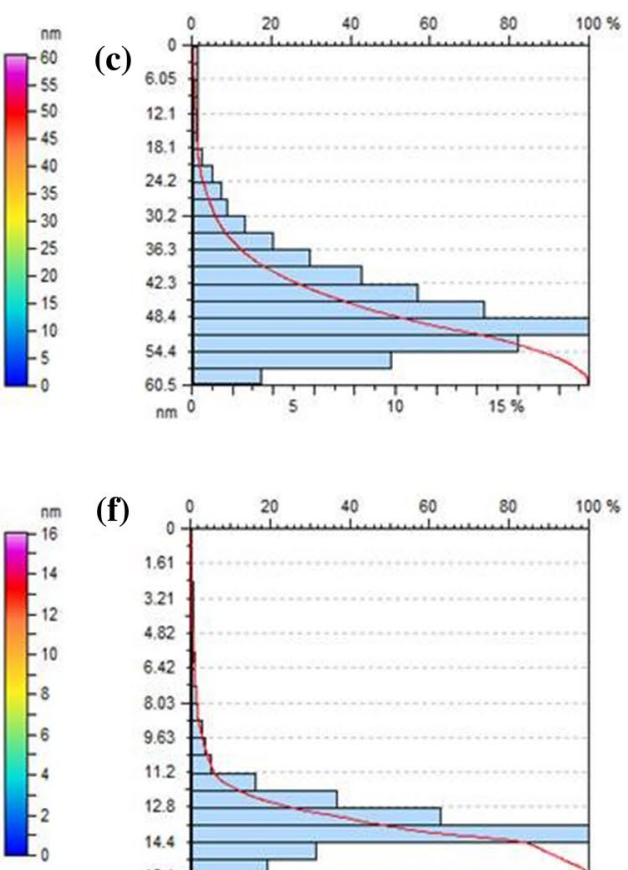

(f)

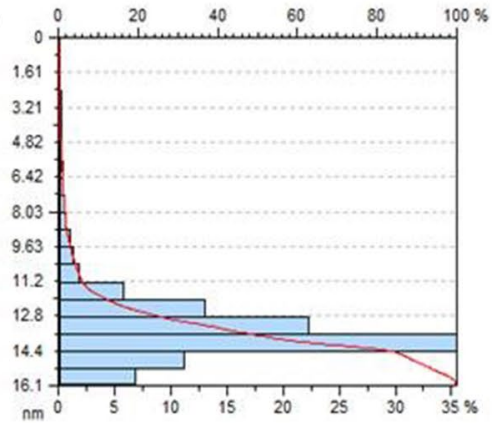

Fig. 3 The morphology of CNPs obtained by AFM at different dilution shows spherical CNPs formed by chemical hydrolysis of fibres with tension. a The 3-dimensional AFM image of a single-diluted sample of CNPs. b Two-dimensional image of a single-diluted sam- ple of CNPs. c Histogram of a single-diluted sample of CNPs. $\mathbf{d}$ The 3-dimensional AFM image of a double-diluted sample of CNPs. e Two-dimensional image of a double-diluted sample of CNPs. $\mathbf{f}$ Histogram of a double-diluted sample of CNPs tension which weakens the hydrogen bonding and minimizes reaction conditions. It is confirmed by wavy XRD pattern of CNPs with no sharp peaks illustrated in the Fig. 6c.

The mechanism of this work explains that the stretched glycosidic linkage and weakened hydrogen bonding ameliorate the vulnerability of fibres to chemical hydrolysis and promotes the formation of spherically wrapped CNPs.

The chemical hydrolysis of cellulose fibres initiates with the reaction of oxygen in glycosidic linkage with hydrogen ion of sulphuric acid that breaks the cellulose chain. The weakened hydrogen bonding of fibres due to tension and heat of hydrolysis facilitate the cellulose chain to wrap into a spherical dimension [16].

The $5 \mathrm{~g}$ of cellulose fibres were chemically hydrolysed and only $0.88 \mathrm{~g}$ of CNPs were collected as resultant after freeze drying. Therefore, the yield of proposed method is $17.6 \%$ by Eq. 5 . During the chemical hydrolysis, most of the cellulose either decomposed into sugar and water or burned by sulphuric acid. Although the overall yield is low but the method is facile and can efficient to produce amorphous spherical CNPs of 8-16 nm. 
Table 2 Quality characteristics of fibres

\begin{tabular}{lll}
\hline Fibres characteristics with units & $\begin{array}{l}\text { Fibres before the drafting-comb- } \\
\text { ing-drafting process }\end{array}$ & $\begin{array}{l}\text { Fibres after the draft- } \\
\text { ing-combing-drafting } \\
\text { process }\end{array}$ \\
\hline Fibrefineness (mtex) & 168 & 185 \\
Maturity (\%) & 87 & 93 \\
Short fibre content (\%) & 12.9 & 8.7 \\
\hline
\end{tabular}

Table 3 Shows the results of uniformity of the fibres tested after the drafting-combingdrafting process

\begin{tabular}{lll}
\hline S. no. & U \% & CVm \% \\
\hline 1 & 2.72 & 3.43 \\
2 & 2.70 & 3.41 \\
3 & 2.73 & 3.40 \\
Mean & 2.72 & 3.42 \\
\hline
\end{tabular}

Yield $=\left(\right.$ mass $_{\mathrm{CNPs}} /$ mass $\left._{\text {fibres }}\right) \times 100$

\subsection{Effect of tension on morphology of CNPs}

AFM images show the spherical morphology of CNPs with different degree of dilution. The Fig. 3a, b illustrates single-diluted CNPs with $18.1 \mathrm{~nm}-60.5 \mathrm{~nm}$ particle size while $48.5 \mathrm{~nm}$ is highly frequent particle size as indicated in its histogram in Fig. 3c. The average particle size is $33.25 \mathrm{~nm}$. The Fig. $3 d$, e show that on double dilution, the size of CNPs reduced up to $8-16.1 \mathrm{~nm}$ while $14.4 \mathrm{~nm}$ is highly frequent particle size as indicated in its histogram in Fig. $3 \mathrm{f}$. The average particle size is $8.8 \mathrm{~nm}$. This is because dilution reduces the agglomeration between CNPs. Therefore, a possible explanation for the production of spherical CNPs at milder conditions can be hypothesised. The draftingcombing-drafting process not only increases the overall crystallite domain by eliminating the amorphous and short fibres but also weakened the disordered domains in the fibres. Consequently, spherical CNPs of 8-16 nm with low crystallinity index when chemically attacked even at milder chemical conditions were achieved.

In closure, the role of tension in fibres should be acknowledged to diminishes the need of sonication/ mechanical agitation before or after chemical hydrolysis and elevated temperature as performed in other reported methods for spherical CNPs $[10,11,22,38,40]$.

\subsection{Effect of tension on uniformity of fibres}

In drafting-combing-drafting process, the combing of cellulose fibres removed the short/immature fibres and impurities which improved the crystallinity index and structural uniformity in them. The fineness of fibres, maturity and amount of short fibre contents before and after the complete process was measured with USTER AFIS (Advanced Fibre Information System) is given in Tables 2, 3.

Table 2 represents the numeric readings about the quality of fibres before and after the process. Finness of fibres is specified by the linear density with unit mtex as given in Eq. 6. These values confirm an increase in linear density from 168 to $185 \mathrm{mtex}$ after the applied process. The percentage maturity of fibres improved after removal of short and immature fibre content calculated by Eq. 7. The maturity of fibres improved from 87 to $93 \%$ when $12.9 \%$
Fig. 4 Spectrograms of Table 3 results
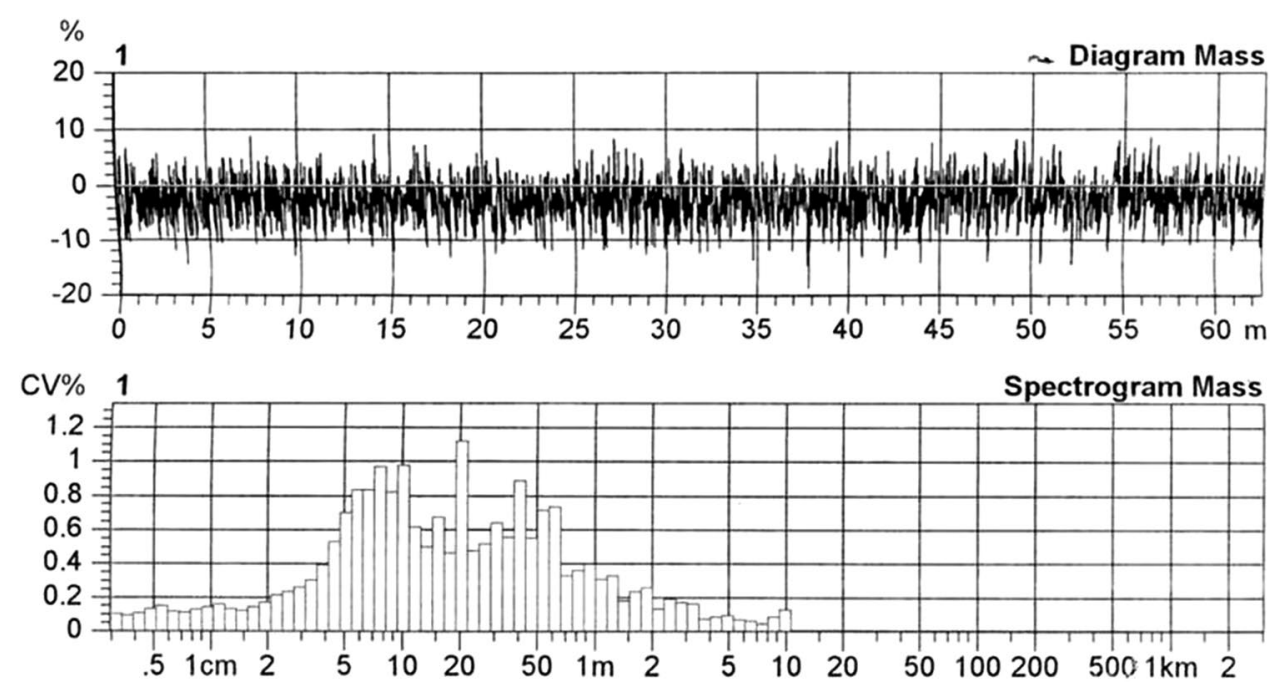

SN Applied Sciences A SPRINGER NATURE journa 

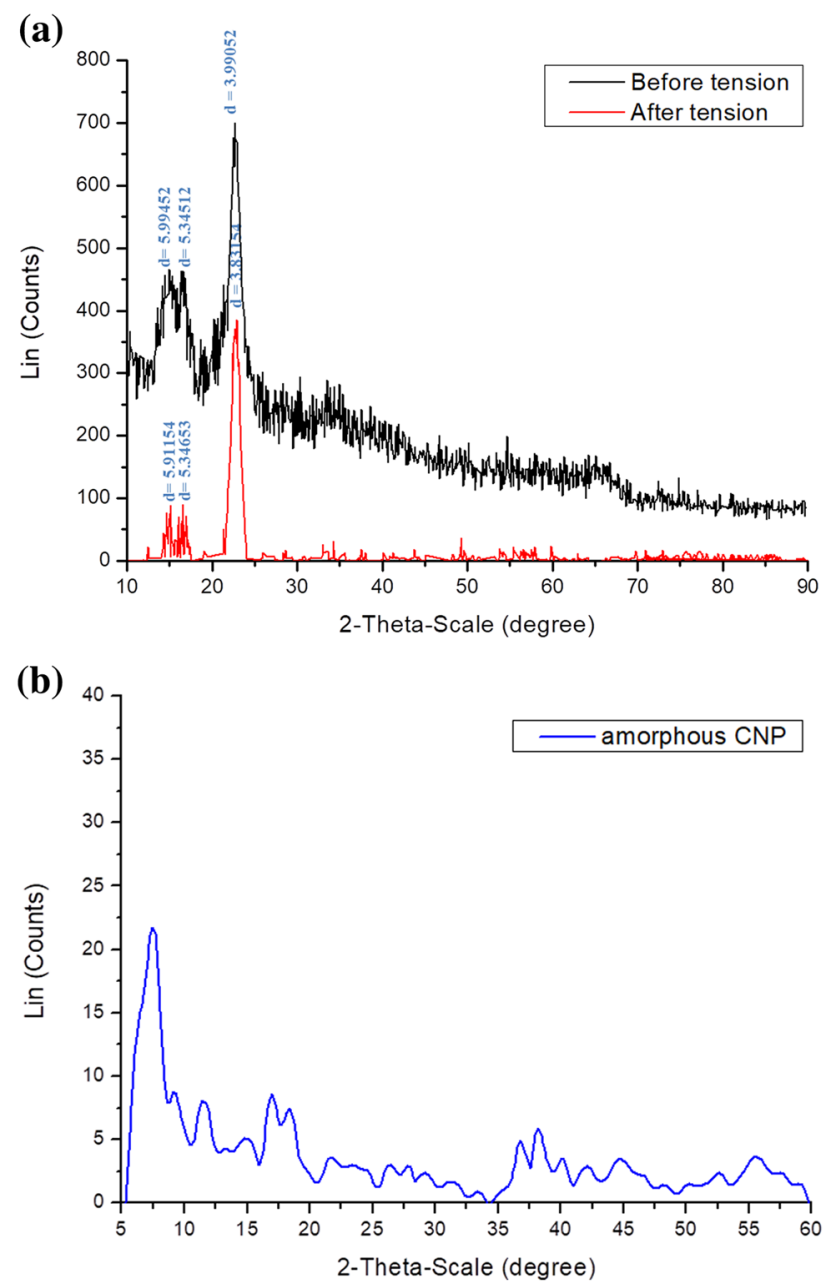

Fig. 5 XRD of cellulose fibres: a before and after tension. $\mathbf{b}$ XRD result of spherical CNPs prepared by chemical hydrolysis of cellulose fibres with tension

short fibre content in sliver was reduced up to $8.7 \%$ by the process estimated by Eq. 8 .

Fibre finness $($ mtex $)=($ mass $(\mathrm{mg})) /($ length $(\mathrm{km}))$

$\%$ Maturity $=($ mass of mature fibres $(\mathrm{mg})) /$

(mass of fibres $(\mathrm{mg})) \times 100$

$\%$ Short Fiber Content $=($ mass of short fibres $(\mathrm{mg})) /$

(mass of fibres $(\mathrm{mg})) \times 100$

Table 3 represents the linear irregularity of fibres or unevenness $(U \%)$ and coefficient of variation in mass of fibres (CV \%). The evenness of fibres was around $97 \%$.

\%Evenness $(\% E v)=100 \%-U \%$
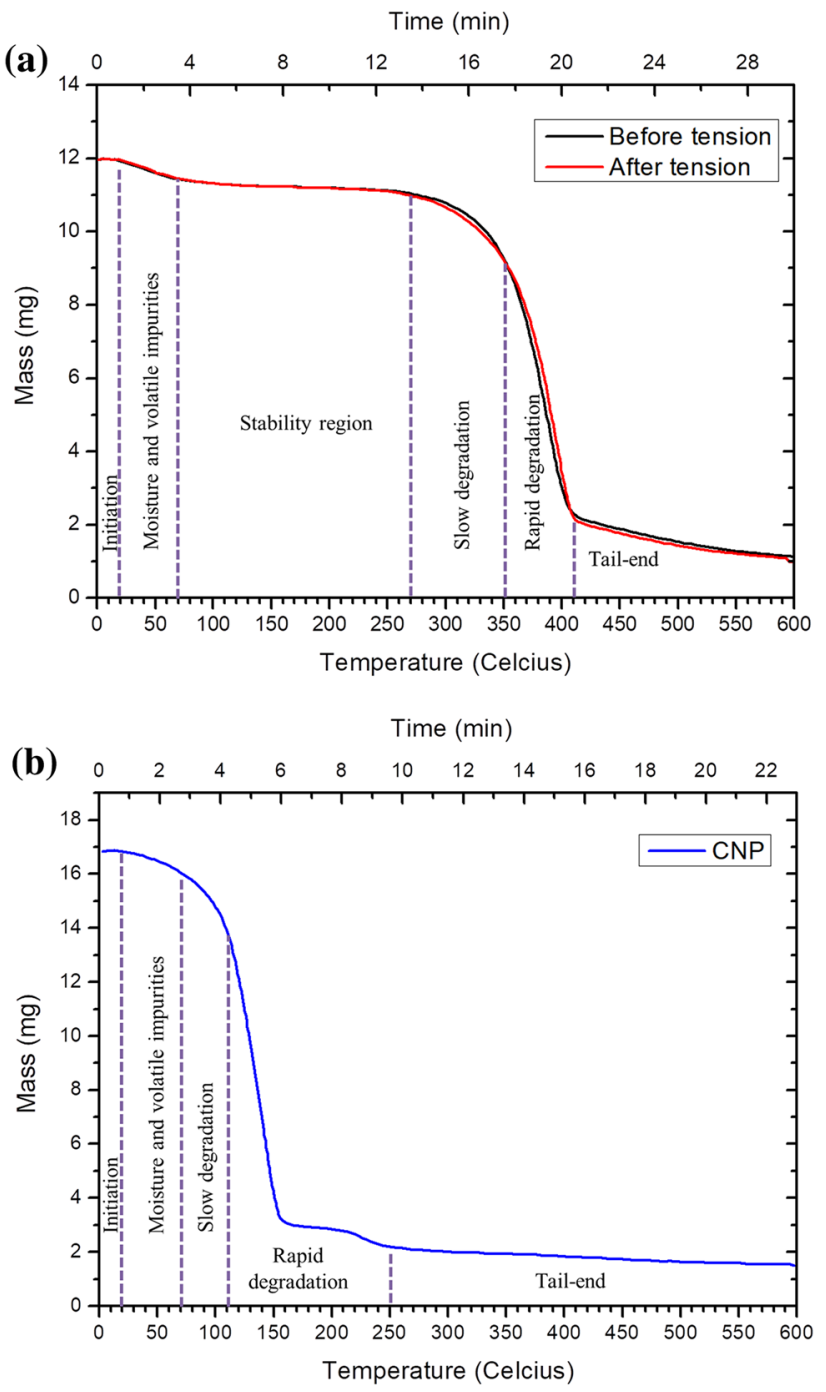

Fig. 6 TGA results of Cellulose fibres: a before and after tension. bTGA of Spherical CNPs prepared by chemical hydrolysis of cellulose fibres with tension

Figure 4 shows the graphical output of the results represented in Table 3. It can be observed from it that CV \% at a wavelength of 1 to $2 \mathrm{~cm}$ is about $0.2 \%$ therefore we considered the $1 \mathrm{~cm}$ long fibres for the preparation of CNPs.

\subsection{Effect of tension on crystallinity index}

The improvement in the crystallinity index can be noticed in the XRD pattern of cellulose fibres before and after the drafting-combing-drafting process as shown in Fig. 5 a. Both the XRD results show similar peak position $(2 \theta)$, such that $23^{\circ}$ for crystallite part at the d-spacing value of $3.8 \AA \mathrm{m}$ and $17^{\circ}$ for the amorphous region with the $d$-spacing value of $5.3 \AA \mathrm{m}$. However, their \% crystallinity index varies due to different peak intensities at certain positions calculated by Eq. 1. This showed that \%C.I of Noil (short 
and immature fibre) to be $55.55 \%$ which increased up to 78.94\% for Sliver(mature fibre) after applying tension. It confirms the effect of tension on crystallinity index such that tension in fibres eliminates much of the amorphous region and improves crystallinity index and uniformity.

Figure $5 \mathrm{~b}$ shows the diffraction pattern of CNPs. The absence of any sharp peak and wave like broadened curves represent the complete distortion of lattice structure and their amorphous nature. This amorphous structure is due to chemical hydrolysis of fibres with tension. As compared to the reported study [14] which explains that the crystalline CNPs should be formed by $55 \%$ $\mathrm{H}_{2} \mathrm{SO}_{4}$ hydrolysis but in this work, amorphous CNPs were achieved due to weaker intermolecular and intramolecular bondings in fibres with tension.

By using the Scherrer Eq. (3) it was evaluated between $5^{\circ}\left(2 \theta_{1}\right)$ to $9^{\circ}\left(2 \theta_{2}\right)$ with FWHM ( $\left.\beta\right)$ of $\pi / 4$ radian which gave the value of $0.184 \mathrm{~nm}$ for crystallite size of CNPs. This proves very low dimension of CNPs 8 to $16 \mathrm{~nm}$ as shown in AFM images in Fig. 3d, e.

\subsection{Effect of tension on thermal properties of cellulose}

Cellulose shows good thermal stability depending upon its primary source [28]. The tension in fibres does not effect in the thermal properties significantly. However, the spherical CNPs showed similar TGA curve as compared to the published literature [22].

The cellulose fibres before and after tension showed almost identical TGA curves as given in Fig. 6a. The TGA was initiated with $12 \mathrm{mg}$ of the sample. A slight downfall of the curve was observed between 20 and $70{ }^{\circ} \mathrm{C}$ which shows the elimination of moisture and volatile impurities. The TGA curve remained steady until $270^{\circ} \mathrm{C}$. This region is known as the stability region. After this, the decomposition of the sample started with a slow pace between 270 and $350^{\circ} \mathrm{C}$ followed by a rapid thermal degradation from 350 to $410^{\circ} \mathrm{C}$. This slow and rapid thermal degradation is due to the carburizing of the sample [39]. The total of $9 \mathrm{mg}$ of sample was carburized. After $410^{\circ} \mathrm{C}$ a smooth decomposition pattern was observed up to $600^{\circ} \mathrm{C}$ which was due to a very minute amount remained for further degradation. This is the tail-end of a TGA curve which means that thermal analysis is over. The TGA curve analysis took $30 \mathrm{~min}$ for complete degradation with $8.3 \%$ charred residue.

The difference between C.I of both types of fibres is just $23.99 \%$. For such a minute amount of samples $(12 \mathrm{mg})$ this difference is not much prominent but the difference in thermal degrading can be significant in bulk amount.

The TGA curve of CNPs is shown in Fig. 6c. The TGA was initiated with $17 \mathrm{mg}$ of the sample. A slight downfall of the curve was observed between 20 and $70{ }^{\circ} \mathrm{C}$ which shows the elimination of moisture and volatile impurities. This decline was further preceded by slow and rapid degradation which ends at $250^{\circ} \mathrm{C}$. It is noted that the due to the high surface area the stability region of CNPs is not prominent in the TGA curve. The steep curve of slow and rapid degradation is due to rapid carburizing. The calculated \% charred residue is $10.6 \%$ while the complete analysis took $22 \mathrm{~min}$.

The TGA of CNPs showed weaker thermal stability than its precursor. This may be due to some sulphate groups that remained in the CNPs after chemical hydrolysis. The elimination of sulphuric acid in sulphated anhydroglucose units consumes less energy which also favours the depolymerisation of cellulose by removing hydroxyl groups via esterification. It also increases surface area and amorphous nature of spherical CNPs and many free end-chains which make them more susceptible to decomposition [30]. This TGA curve explains the role of hydrogen bonding and glycosidic linkages. The inter-molecular bonding in cellulose improves its overall physical strength. At nano-level cellulose fibres have fewer numbers of inter-molecular bonding among them due to their low degree of polymerization, which declined overall thermal stability [5]. Therefore, CNPs have higher \% charred residue but weaker thermal stability than their precursors. Additionally, flame retardant sulphate groups contribute to the increased \%charred residue [30].

\subsection{Applications}

CNPs already play a vital role as a raw material in fabrication of various daily-life products and composites due to their very small size, good compaction $[23,31]$, low toxicity [29] and other beneficial properties with respect to its surface area $[7,41]$. Our CNPs with a very small size of 8 to $16 \mathrm{~nm}$ can dramatically improve compaction and product efficiency with less amount and energy consumption.

However, our declared process itself has its contribution to the mass production of CNPs both in the industry and chemical laboratories due to its simplicity and efficiency. Furthermore, we claim its good yield due to less processing complications and possible use of short fibre waste for green processing as reported [9], because these short fibres also possess some amount of tension in them.

\section{Conclusions}

In conclusion, the tension in fibres by drafting-combing-drafting process produced uniformity and high crystallinity index in cotton cellulose fibres and has played its significant role in the preparation of spherical CNPs. The spherical CNPs of 8-16 nm diameter were prepared 
successfully with low crystallinity index using milder reaction conditions without any mechanical stirring or sonification and elevated temperature. TGA results showed the negligible effect of tension on thermal properties due to the very small amount of sample.

Acknowledgements Authors are thankful for Mr. Aqil Usmani, Quality Manager at Fazal Textile Mills, Karachi to provide fibres and its testing facilities and Dr. Khalid M. Khan and Dr. Raza Shah, HEJ Research Centre, Karachi for AFM of our samples.

\section{Compliance with ethical standards}

Conflict of interest The authors declare that they have no conflict of interest.

\section{References}

1. Abe K, Yano H (2012) Cellulose nanofiber-based hydrogels with high mechanical strength. Cellulose 19(6):1907-1912. https:// doi.org/10.1007/s10570-012-9784-3

2. Altaner CM, Thomas LH, Fernandes AN, Jarvis MC (2014) How cellulose stretches: synergism between covalent and hydrogen bonding. Biomacromol 15(3):791-798. https://doi.org/10.1021/ bm401616n

3. Bereznitski Y, LoBrutto R, Variankaval N, Thompson R, Thompson $\mathrm{K}$, Sajonz R et al (2002) Mechanistic aspects of chiral discrimination on an amylose tris(3,5-dimethylphenyl)carbamate. Enantiomer 7(6):305-315. https://doi.org/10.1080/102424302900159 08

4. Czaja W, Krystynowicz A, Bielecki S, Brown RM (2006) Microbial cellulose - the natural power to heal wounds. Biomaterials 27(2):145-151. https://doi.org/10.1016/j.biomateria Is.2005.07.035

5. Das K, Ray D, Bandyopadhyay NR, Sengupta S (2010) Study of the properties of microcrystalline cellulose particles from different renewable resources by XRD, FTIR, nanoindentation, TGA and SEM. J Polym Environ 18(3):355-363. https://doi. org/10.1007/s10924-010-0167-2

6. Djahedi C, Bergenstråhle-Wohlert M, Berglund LA, Wohlert $J$ (2016) Role of hydrogen bonding in cellulose deformation: the leverage effect analyzed by molecular modeling. Cellulose 23(4):2315-2323. https://doi.org/10.1007/s10570-016-0968-0

7. Eichhorn SJ (2011) Cellulose nanowhiskers: promising materials for advanced applications. Soft Matter 7(2):303. https://doi. org/10.1039/c0sm00142b

8. Enomoto-Rogers $\mathrm{Y}$, Kamitakahara H, Yoshinaga A, Takano $T$ (2011) Water-soluble low-molecular-weight cellulose chains radially oriented on gold nanoparticles. Cellulose 18(4):929-936. https://doi.org/10.1007/s10570-011-9535-x

9. Fattahi Meyabadi T, Dadashian F, Mir Mohamad Sadeghi G, Ebrahimi Zanjani Asl H (2014) Spherical cellulose nanoparticles preparation from waste cotton using a green method. Powder Technol 261:232-240. https://doi.org/10.1016/j.powtec.2014.04.039

10. Filson PB, Dawson-andoh BE (2009) Bioresource Technology Sono-chemical preparation of cellulose nanocrystals from lignocellulose derived materials. Biores Technol 100(7):2259-2264. https://doi.org/10.1016/j.biortech.2008.09.062

11. Han J, Zhou C, French AD, Han G, Wu Q (2013) Characterization of cellulose II nanoparticles regenerated from 1-butyl-3-methylimidazolium chloride. Carbohydr Polym 94(2):773-781. https ://doi.org/10.1016/j.carbpol.2013.02.003
12. Haywood AD, Davis VA (2016) Effects of liquid crystalline and shear alignment on the optical properties of cellulose nanocrystal films. Cellulose. https://doi.org/10.1007/s10570-016-1150-4

13. Ioelovich $M$ (2008) Cellulose as a nanostructured polymer: a short review. BioResources 3(4):1403-1418

14. Ioelovich $M$ (2012) Optimal conditions for isolation of nanocrystalline cellulose particles. Nanosci Nanotechnol 2(2):9-13. https ://doi.org/10.5923/j.nn.20120202.03

15. loelovich M, Leykin A, Figovsky O (2010) Study of cellulose paracrystallinity. BioResources 5(3):1393-1407

16. Johar N, Ahmad I, Dufresne A (2012) Extraction, preparation and characterization of cellulose fibres and nanocrystals from rice husk. Ind Crops Prod 37(1):93-99. https://doi.org/10.1016/j.indcr op.2011.12.016

17. Kalia S, Dufresne A, Cherian BM, Kaith BS, Av L, Njuguna J, Nassiopoulos E (2011) Cellulose-based bio- and nanocomposites: a review. Int J Polym Sci. https://doi.org/10.1155/2011/837875

18. Khalid A, Khan R, UI-Islam M, Khan T, Wahid F (2017) Bacterial cellulose-zinc oxide nanocomposites as a novel dressing system for burn wounds. Carbohydr Polym 164:214-221. https://doi. org/10.1016/j.carbpol.2017.01.061

19. Lavanya D, Kulkarni PK, Dixit M, Prudhvi Kanth Raavi LNVK (2015) Sources of cellulose and their applications-a review. Int J Drug Formul Res 2(November):19-38

20. Lavoine N, Desloges I, Dufresne A, Bras J (2012) Microfibrillated cellulose-its barrier properties and applications in cellulosic materials: a review. Carbohydr Polym 90(2):735-764. https://doi. org/10.1016/j.carbpol.2012.05.026

21. Loloei M, Rezaee A, Roohaghdam AS, Aliofkhazraei M (2017) Conductive microbial cellulose as a novel biocathode for $\mathrm{Cr}(\mathrm{VI})$ bioreduction. Carbohydr Polym 162:56-61. https://doi. org/10.1016/j.carbpol.2017.01.046

22. Lu P, Hsieh Y Lo (2010) Preparation and properties of cellulose nanocrystals: rods, spheres, and network. Carbohydr Polym 82(2):329-336. https://doi.org/10.1016/j.carbpol.2010.04.073

23. Mariano M, El Kissi N, Dufresne A (2016) Cellulose nanocrystal reinforced oxidized natural rubber nanocomposites. Carbohydr Polym 137:174-183. https://doi.org/10.1016/j.carbp ol.2015.10.027

24. Mohd Amin MCl, Ahmad N, Halib N, Ahmad I (2012) Synthesis and characterization of thermo- and pH-responsive bacterial cellulose/acrylic acid hydrogels for drug delivery. Carbohydr Polym 88(2):465-473. https://doi.org/10.1016/j.carbp ol.2011.12.022

25. Moon RJ, Martini A, Nairn J, Simonsen J, Youngblood J (2011) Cellulose nanomaterials review: structure, properties and nanocomposites. Chem Soc Rev. https://doi.org/10.1039/c0cs00108b

26. Okiyama A, Motoki M, Yamanaka S (1992) Bacterial cellulose II. Processing of the gelatinous cellulose for food materials. Food Hydrocolloids 6(5):479-487. https://doi.org/10.1016/S0268 -005X(09)80033-7

27. Park S, Baker JO, Himmel ME, Parilla PA, Johnson DK (2010) Cellulose crystallinity index: measurement techniques and their impact on interpreting cellulase performance. Biotechnol Biofuels 3(1):10. https://doi.org/10.1186/1754-6834-3-10

28. Ramiah MV (1970) Thermogravimetric and differential thermal analysis of cellulose, hemicellulose, and lignin. J Appl Polym Sci 14(5):1323-1337. https://doi.org/10.1002/app.1970.070140518

29. Roman M (2015) Toxicity of cellulose nanocrystals: a review. Ind Biotechnol 11(1):25-33. https://doi.org/10.1089/ind.2014.0024

30. Roman M, Winter WT (2004) Effect of sulfate groups from sulfuric acid hydrolysis on the thermal degradation behavior of bacterial cellulose. Biomacromolecules 5(5):1671-1677. https://doi. org/10.1021/bm034519+

31. Rubentheren V, Ward TA, Chee CY, Nair P, Salami E, Fearday $C$ (2016) Effects of heat treatment on chitosan nanocomposite 
film reinforced with nanocrystalline cellulose and tannic acid. Carbohydr Polym 140:202-208. https://doi.org/10.1016/j.carbp ol.2015.12.068

32. Shafiei-Sabet S, Hamad WY, Hatzikiriakos SG (2014) Ionic strength effects on the microstructure and shear rheology of cellulose nanocrystal suspensions. Cellulose 21(5):3347-3359. https://doi.org/10.1007/s10570-014-0407-z

33. Shafiei-Sabet S, Martinez M, Olson J (2016) Shear rheology of micro-fibrillar cellulose aqueous suspensions. Cellulose 23(5):2943-2953. https://doi.org/10.1007/s10570-016-1040-9

34. Shen T, Gnanakaran S (2009) The stability of cellulose: a statistical perspective from a coarse-grained model of hydrogen-bond networks. Biophys J 96(8):3032-3040. https://doi.org/10.1016/j. bpj.2008.12.3953

35. Stanković SB, Popović D, Poparić GB (2008) Thermal properties of textile fabrics made of natural and regenerated cellulose fibers. Polym Test 27(1):41-48. https://doi.org/10.1016/j.polym ertesting.2007.08.003

36. Thygesen $A$, Oddershede J, Lilholt $H$, Thomsen AB, Sta $K$ (2005) On the determination of crystallinity and cellulose content in plant fibres. Cellulose. https://doi.org/10.1007/s1057 0-005-9001-8
37. Wainstein J, Fasce LA, Cassanelli A, Frontini PM (2007) High rate toughness of ductile polymers. Eng Fract Mech 74(13):2070 2083. https://doi.org/10.1016/j.engfracmech.2006.10.001

38. Xiong R, Zhang X, Tian D, Zhou Z, Lu C (2012) Comparing microcrystalline with spherical nanocrystalline cellulose from waste cotton fabrics. Cellulose 19(4):1189-1198. https://doi. org/10.1007/s10570-012-9730-4

39. Yang $\mathrm{H}$, Yan $\mathrm{R}$, Chen $\mathrm{H}$, Lee $\mathrm{DH}$, Zheng $\mathrm{C}$ (2007) Characteristics of hemicellulose, cellulose and lignin pyrolysis. Fuel 86(1213):1781-1788. https://doi.org/10.1016/j.fuel.2006.12.013

40. Zhang J, Elder TJ, Pu Y, Ragauskas AJ (2007) Facile synthesis of spherical cellulose nanoparticles. Carbohydr Polym 69(3):607611. https://doi.org/10.1016/j.carbpol.2007.01.019

41. Zhou C, Wu Q (2012) Recent Development in applications of cellulose nanocrystals for advanced polymer-based nanocomposites by novel fabrication strategies. https://doi. org/10.5772/46512

Publisher's Note Springer Nature remains neutral with regard to jurisdictional claims in published maps and institutional affiliations. 